Eric Obershaw. Metadata for Resource Description on Corporate Intranets. A Master's paper for the M.S. in L.S. degree. April, 2001. 26 pages. Advisor: Jane Greenberg.

Since resource discovery has become a difficult and time-consuming task, some corporations are instituting metadata initiatives to alleviate these problems. This paper reports on an exploratory study of the metadata schemas supporting corporate intranets. The study consists of two parts; an examination of the metadata elements currently in use for corporate intranets and a comparison of these elements to the schema developed by the Dublin Core Metadata Initiative. Schemas were collected from ten such corporations and the aggregate data was examined to uncover what types of elements are likely to be important for resource description on a corporate intranet. The results found that thirteen of the fifteen metadata elements most commonly used by schemas in this study are supported by the Dublin Core. An additional 20 elements not supported by the Dublin Core were also found. These additional elements show how corporations can enhance the Dublin Core to meet the needs of their own intranet.

Headings:

Cataloging
Dublin Core
Information retrieval
Intranets
Metadata
Online searching




\title{
METADATA FOR RESOURCE DESCRIPTION ON CORPORATE INTRANETS
}

by

Eric Obershaw

\begin{abstract}
A Master's Paper submitted to the faculty of the School of information and Library Science of the University of North Carolina at Chapel Hill in partial fulfillment of the requirements for the degree of Master of Science in Library Science
\end{abstract}

Chapel Hill, North Carolina

April, 2001

Approved by:

Advisor 


\section{Contents}

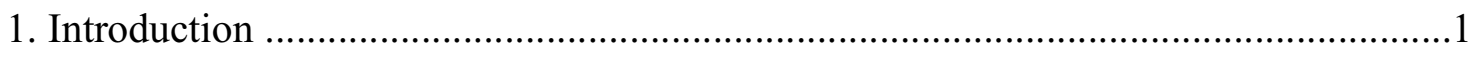

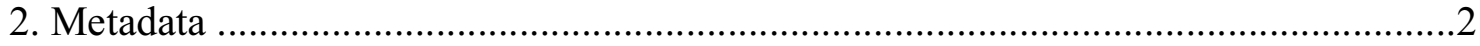

3. Corporate Intranets and Resource Discovery ..................................................5

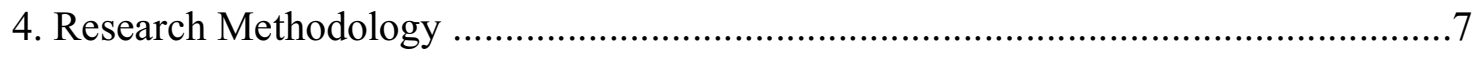

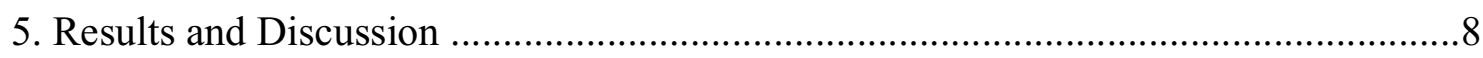

6. Conclusions ….......................................................................................... 18

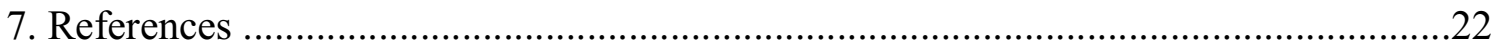

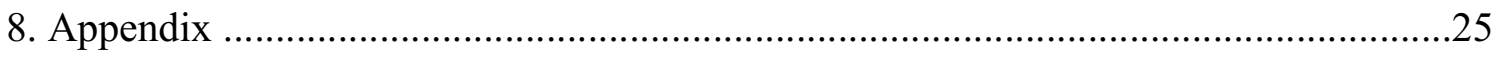




\section{Introduction}

Large corporations not only produce vast amounts of information on a daily basis; they also purchase great numbers of technical reports, industry analyses, and primary research to support various business operations. "Knowledge is power," one of the popular buzz phrases of the nineties, reflects this dependence on information. Information does not necessarily equal knowledge, but poor access to information impedes innovation and knowledge creation. With this in mind, large organizations have looked to the Internet as a way to increase communication, disseminate information, and thereby stimulate innovation within their organizations. Most large organizations today have adopted Internet technologies to create proprietary Internets (called intranets) that span the entire organization to facilitate this communication.

Some organizations have reached a critical stage in terms of access to information assets on their intranets. When the opportunity costs of seeking certain information outweigh the value of the information sought, users are likely to abandon their search. Some such organizations are creating their own metadata schemas to describe the information assets on local intranets to aid in information search and retrieval (Doran 1999, Shearer \& Absher 1999). Some intranet search software packages, such as those by Verity (http://www.verity.com), have responded to this trend by integrating support for metadata and customizable fields for the indexing and searching of information.

This paper reports on an exploratory study of the metadata schemas supporting corporate intranets. The study consists of two parts; an examination of the metadata 
elements currently in use for corporate intranets and a comparison of these elements to the schema developed by the Dublin Core Metadata Initiative (DCMI). The Dublin Core Element Set was selected as a basis for developing a full-featured intranet metadata schema because it was designed to be discipline independent and versatile enough to allow communities to enhance it according to their own specific needs.

The Dublin Core Element Set was also selected because no metadata standards have yet been developed specifically for the corporate intranet. This is likely due to the fact that each organization has specific needs based on unique types of documents, management styles, corporate cultures, and archiving practices. That is not to say, however, that organizations would not benefit from a systematic study or evaluation of case studies about metadata schemas in other organizations.

\section{Metadata}

The unfathomable number of documents on the World Wide Web (WWW) has made searching for information a daunting task. Google, the largest search engine, directly indexes over 602 million webpages (Sullivan 2000). Through its link analysis algorithms an additional 600-700 million webpages can be returned by user queries (Sullivan 2000). As of this writing, Google boasts of covering over 1.3 billion webpages (Google 2000). Even a well-formed query into an index of this size can retrieve thousands of hits. Hahn (1998) states that "few actual users of Web search engines understand how to manipulate and control a query to maximize the quality of their retrieval ... most users still retrieve documents that have little or nothing to do with the topic of interest." 
Search engines attempt to alleviate the problems of high retrieval and low precision on the WWW by developing new proprietary algorithms for relevancy ranking and indexing. While this may help improve the ranking of the top few documents retrieved when compared to the total number of hits, it does relatively little for the user who is looking for a specific document. For example, if a student studying speeches by Bill Clinton performed a basic WWW search for "bill clinton and speeches" it would be impossible to distinguish pages about speeches given by Bill Clinton as opposed to the thousands of pages that merely mention him in the full text.

In the Hypertext Markup Language (HTML), <meta $>$ tags were originally intended to bring order to this chaos. Users could insert $<$ meta $>$ tags into the $<$ head $>$ element of any HTML document to assist web-indexing spiders in the accurate indexing of their sites. Medeiros (2000) described how some web site creators discovered they could exploit this indexing technique and make their sites appear higher on search engine hit lists by overloading the $<$ meta $>$ tags with remotely related or even completely irrelevant terms. This caused many search engines to discontinue indexing $<$ meta $>$ tags or at least to seriously reconsider how they index them.

These $<$ meta $>$ tags are one instance of what can be called metadata, data about data. Metadata is a description of a given document or information resource. In more formal approaches, this description follows a specific set of rules called a schema. The purpose of metadata is to aid in the successful retrieval of a given source of information by looking at a surrogate for the source (i.e., the metadata), which contains the most critical information for determining a source's usability or relevance. Metadata initiatives have been around for a long time; they simply have not been called 
"metadata." A bibliographic record in a library catalog is one example of metadata. The bibliographic record contains all the essential information about the item it describes including title, author, publisher, date, location, size, and subjects covered.

While metadata may help alleviate some of the problems of relevant document retrieval by web-based search engines, a study by Qin and Wesley (1998) that examined the content of $<$ meta $>$ tags for 1037 web documents found a great number of $<$ meta $>$ tags that were used incorrectly even though the creators did not seem to be intentionally doing so. Most mistakes involved improper coding of the metadata tags, while other mistakes were generally empty elements, improper use of vocabularies, and repetition of nonrepeatable elements.

This study suggests that some of these problems may be due to the lack of a formalized schema. It also seems that the proper use of metadata elements must be emphasized to insure their effective usage. If metadata is ever expected to gain wide application by authors of typical web documents, there must be simple instructions and people need to be made cognizant of how careful creation of metadata will make their pages more accessible to the community. This is an area where webpage editors could be of use in writing the syntax for author-supplied data.

A formal metadata schema, while not resolving the problem of $<$ meta $>$ tag misuse or abuse, is a more systematic attempt to organize the internet and its vast information resources. The Dublin Core is one of the most widely used metadata standards. As stated by the DCMI (2000), the Dublin Core was developed from an "interdisciplinary consensus" about what are the most basic and necessary elements to support successful resource discovery. The Dublin Core's chief advantage is that it is extensible which 
allows anyone to create a schema based on the DC with unique elements for a specific situation.

Forsberg (2000) discusses how any metadata schema must take into consideration the context of business in which the corporation is engaged. He also notes that not all resources are webpages and not all web resources are static. Dempsey and Heery (1998) predict that a variety of users will create and modify metadata records for their own purposes. For example, creators will provide a simple bibliographic description; a network administrator may add elements for access, file format, and transaction logs; and information managers may enhance the record with further metadata for records management and archival purposes. These are trends that intranet developers need to be aware of in order to create metadata schemas that can be used by the widest possible audience

\section{Corporate Intranets and Resource Discovery}

Albert (2000) discusses how it is very easy to post a functional website within a day, but at some point "intranets need architecture too... it takes considerable growth before the dangers of a lack of infrastructure become obvious to users and decisionmaking executives." If intranet managers wait until this point to design and implement an information architecture, it would take considerable effort to change the state of the intranet and potentially valuable information may have been lost in the meanwhile.

A study by the Working Council for Chief Information Officers (2000) also shows that corporate intranets are typically built in a bottom-up fashion by individual business units. They show that "individual units are managing their own intranets 
without enterprise-wide coordination, amplifying information redundancy, and missing opportunities to create economies of scale during the development process."

The same study reports on findings by several corporations that are experiencing difficulties with information retrieval on their intranets. A 1997 survey of Ford employees indicated that they could find only $15 \%$ of the intranet information they required to do their work. In a business environment, having to weed through potentially hundreds of local documents to retrieve desired information can be very costly. Sun Microsystems calculated a $\$ 10$ million per year loss from users wasting time looking for information on the intranet due to inconsistent navigational structures. These examples show that the opportunity costs of disorganized content on the intranet can be very high. Metadata, however, can help address some of these problems.

Metadata is not only a useful method for managing information; it should be considered an essential tool for enabling business critical decisions. Using data or information from an outdated report for critical decisions could lead to drastic failures. Varon (2000) discusses the knowledge management issues at the Central Intelligence Agency (CIA). It has been suggested that outdated maps led to the accidental bombing of the Chinese embassy in Belgrade. The CIA knowledge management team turned to the CIA librarians and their internal subject taxonomies to create a useful metadata schema to prevent further intelligence blunders.

A review of the literature indicates how current metadata initiatives have developed for the World Wide Web and why a schema is necessary for resource creators to apply metadata. Studies of metadata for corporate intranets mainly focus on an individual project. Others simply mention metadata in general discussions of knowledge 
management or content management. The studies about intranets show that the costs are high for organizations whose intranets have expanded beyond the point where basic search engines can reliably retrieve relevant information. Given that there is no standard metadata schema for corporate intranets and the utility of Dublin Core has not been explored for this unique situation, this research will attempt to fill that gap by examining currently used metadata and by evaluating the Dublin Core as a basis for an intranet metadata schema.

\section{Research Methodology}

This research paper is an exploratory study of metadata elements currently used to support corporate intranets. The research method used for this investigation was to gather metadata schemas from as many organizations as possible, create a crosswalk analysis of these schemas, and compare them with the Dublin Core.

Initially, an e-mail request was sent to several business and corporate library related mailing lists - the SLA-BF, SLA-DITE, and BUSLIB-L - seeking research participants. These mailing lists were selected because they reach thousands of corporate librarians around the world who are actively engaged in information services in their respective companies. Though not all metadata schemas are controlled by corporate libraries, librarians often have input into the schema or are likely to know whom to contact for the needed information. Presuming that larger corporations have larger intranets and are therefore more likely to have developed a schema for document description and management, letters were also sent to those Fortune 100 companies (Fortune 2001) that had a corporate library. Of the ten schemas collected, there was one 
from published literature, three from the mailing lists, three from the directly mailing to Fortune 100 companies, and three from personal contacts in corporations.

Part of the agreement sent to contributing organizations was that their names would not be disclosed in any way. Once the schemas were collected, they were each given a number to protect the privacy of the contributing corporation and then mapped to each other and to the Dublin Core creating a crosswalk analysis (Appendix A). This is a map that matches the semantic meaning of elements to like elements in other schemas. The Dublin Core element set was chosen as the basis for comparison because its relatively small number of essential elements and its extensible nature make it an ideal framework from which to build a unique full-featured schema.

After creating a crosswalk analysis of these schemas in a spreadsheet, a combined set of all the distinct elements could be extracted. From this data it is possible to examine how Dublin Core elements are utilized on the corporate intranet in addition to any unique elements not supported by the Dublin Core.

\section{Results and Discussion}

A total of ten schemas were collected, six of which were accompanied by internal documentation about the schema and intranet publishing within the organization. With the exception of one company, all are listed in the top 100 of the Fortune 500 list and all are large multinational corporations with at least one office outside North America.

The ten schemas contain a combined total of 40 distinct elements. The schema with the fewest distinct elements had nine while the one with the most distinct elements had 25. This gives a standard deviation of 5.2 elements. The test for outliers shows that 
no schemas appear in the top five or the bottom five per cent of data, indicating that all schemas fall within the normal range for this data set.

With this information it is possible to analyze the utility of the Dublin Core for corporate intranets. Twenty elements not supported by the Dublin Core including PRODUCT, SECURITY, CONTACT and AUDIENCE among others, appear in the 40 unique elements found. These elements reveal how corporations might extend the Dublin Core to meet their local needs. A total of 40 distinct elements were found in the ten schemas, but eleven of those 40 appeared only once among all schemas. The crosswalk analysis of schemas is located in the Appendix.

A number of schemas contain metadata elements that can be considered variations of a more general element. For example, DATE_MODIFIED and DATE_CREATED are a more specific variation of a general DATE element. There is a version of Dublin Core called Qualified Dublin Core (DCMI 2000) that uses “dot notation” to specify a particular meaning for a given element. In the previous example, DATE_MODIFIED and DATE_CREATED would be expressed as DATE.MODIFIED and DATE.CREATED. When creating the crosswalk analysis and aggregating the data from the ten schemas, the practices of Qualified Dublin Core were followed to reflect this level of granularity for some elements as it permits a more accurate mapping of the elements.

A summary of all the elements found in the ten corporate intranet metadata schemas appears in Table 1. DC has been placed before all metadata elements supported by the Dublin Core. Fifteen elements appear in the basic unqualified Dublin Core, but in the following table more than 15 elements have the "DC" prefix because each qualified element is displayed individually to reveal the granularity of the schemas studied. 
Table 2

Metadata Elements and Their Frequencies

\begin{tabular}{lclc}
\hline Elements & Schemas* & Elements & Schemas \\
\hline DC.DESCRIPTION & 10 & CONTACT.ADDRESS & 3 \\
\hline DC.TITLE & 9 & CONTACT.OTHER & 3 \\
\hline DC.CREATOR & 9 & STATUS & 3 \\
\hline DC.SUBJECT & 8 & LOCATION & 3 \\
\hline DC.PUBLISHER & 8 & DC.COVERAGE & 2 \\
\hline DC.DATE.CREATED & 8 & PRODUCT & 2 \\
\hline DC.TYPE & 7 & INDEXED & 2 \\
\hline DC.LANGUAGE & 7 & AUDIENCE & 2 \\
\hline DC.SUBJECT.KEYWORDS & 6 & DATE.PROCESSED & 1 \\
\hline DC.DATE.VALID & 6 & MEDIA (ORIGINAL) & 1 \\
\hline DC.FORMAT & 6 & PRODUCT.FAMILY & 1 \\
\hline DC.IDENTIFIER & 6 & PRODUCT.CATEGORY & 1 \\
\hline DC.DATE.MODIFIED & 5 & PRODUCT.PILLAR & 1 \\
\hline CONTACT.NAME & 5 & CUSTOMER_SOLUTION & 1 \\
\hline SECURITY & 5 & PROJECT & 1 \\
\hline DC.CONTRIBUTOR & 4 & NOTES & 1 \\
\hline DC.RELATION & 4 & ACCESS & 1 \\
\hline DC.FORMAT.SIZE & 3 & METADATA ID & 1 \\
\hline DC.SOURCE & 3 & RATING & 1 \\
\hline DC.RIGHTS & 3 & RETENTION PERIOD & 1 \\
\hline
\end{tabular}

*number of schemas where the element appeared

The mean number of distinct elements found per schema is 15.7 and the median is 13.5. When calculating the mean number of Dublin Core elements in a schema, modified elements (e.g., DATE.CREATED, DATE.MODIFIED, DATE.VALID) were counted as a single element in order to map them to the Dublin Core more readily. The mean and the median number of elements are very close to the number of elements present in the Dublin Core (15). This does not, however, mean that nearly all Dublin Core elements appear in every schema. Only one schema was found to contain all 15 of the Dublin Core 
elements. The fewest found in a schema was six elements. The mean number of Dublin Core elements present was 9.5 and the median was 8.5 .

As shown in Table 2, a total of 15 distinct elements appear in at least half of the schemas studied. Thirteen of these 15 elements are semantically equivalent to Dublin Core metadata elements. The two elements found but not supported by the Dublin Core are CONTACT.NAME and SECURITY, each of which appears five times among all the schemas. These two appear to be important for intranets.

CONTACT.NAME is important for identifying the party responsible for the maintenance of a resource. In a fluid organization where individuals move across teams, divisions and locations frequently, the person listed as the creator may not be the principal maintainer of the resource. Of the five schemas with a CONTACT element, only three of them have a separate element for the CONTACT.ADDRESS. The other four either do not record where to reach the contact person or they record the address along with the person's name in the same field. Additionally, three of these schemas also have another element for entities such as manager, team, and support beyond the principal CONTACT element. 
Table 2

Metadata Elements Appearing in 5 or more Schemas

\begin{tabular}{|c|c|c|}
\hline Elements & Schemas & Description \\
\hline DC.DESCRIPTION & 10 & $\begin{array}{l}\text { Abstract or phrases describing the } \\
\text { resource }\end{array}$ \\
\hline DC.TITLE & 9 & Title of resource being cataloged \\
\hline DC.CREATOR & 9 & Author or creator of the resource \\
\hline DC.SUBJECT.CONTROLLED & 8 & $\begin{array}{l}\text { Subject words chosen from a controlled } \\
\text { vocabulary }\end{array}$ \\
\hline DC.PUBLISHER & 8 & $\begin{array}{l}\text { Business unit responsible for the creation } \\
\text { or distribution of the resource, sometimes } \\
\text { external publishers }\end{array}$ \\
\hline DC.DATE.CREATED & 8 & Date the resource was authored \\
\hline DC.TYPE & 7 & Genre or purpose of the resource \\
\hline DC.LANGUAGE & 7 & Language of the resource \\
\hline DC.SUBJECT.KEYWORDS & 6 & $\begin{array}{l}\text { Uncontrolled keywords that describe the } \\
\text { resource }\end{array}$ \\
\hline DC.DATE.VALID & 6 & $\begin{array}{l}\text { Date unto which the resource is made } \\
\text { available or should be considered valid }\end{array}$ \\
\hline DC.FORMAT & 6 & $\begin{array}{l}\text { Physical manifestation of the resource } \\
\text { including media, size, length, etc. }\end{array}$ \\
\hline DC.IDENTIFIER & 6 & $\begin{array}{l}\text { Unique identifier (URL, accession } \\
\text { number, etc) }\end{array}$ \\
\hline DC.DATE.MODIFIED & 5 & Date last modified \\
\hline CONTACT.NAME & 5 & $\begin{array}{l}\text { Person or body responsible for the } \\
\text { maintenance or administration of the } \\
\text { resource }\end{array}$ \\
\hline SECURITY & 5 & $\begin{array}{l}\text { Minimum security level required to access } \\
\text { the resource }\end{array}$ \\
\hline
\end{tabular}

The SECURITY element shows a unique aspect of the corporate intranet that necessitates an enhancement of Dublin Core if the Dublin Core is to be used in this environment regularly. A company would understandably be cautious about making information freely available over the intranet if that information could compromise competitiveness. Minimally, the metadata element SECURITY records the minimum 
required security clearance for users of the resource. Ideally, a system could be devised whereby a search would automatically screen out documents if the user did not have a sufficient security clearance.

One of the companies that contributed a schema to this research has such a system in place. In order for a user to enter one of the many portals on the intranet he/she must $\log$ in. As a part of this log in procedure the portal is configured to the user's preferences and security clearance. Any searches through the search engine also take this into account and only return results for which the user has authorization.

Five of the Dublin Core elements (Table 3) occur in less than half of the schemas studied. This could indicate that in the environment of the corporate intranet, these aspects of an information resource are not considered crucial to finding or maintaining it.

Table 3

Less Frequently Occurring Dublin Core Elements

\begin{tabular}{lcl}
\hline \multicolumn{1}{c}{ Elements } & Schemas & $\begin{array}{l}\text { Description } \\
\text { Other persons or bodies involved in the creation of } \\
\text { the resource }\end{array}$ \\
\hline DC.RELATION & 4 & $\begin{array}{l}\text { Resources related to the present resource by } \\
\text { derivation, or similar subject content }\end{array}$ \\
\hline DC.FORMAT.SIZE & 3 & $\begin{array}{l}\text { Physical memory required for the resources } \\
(52 \mathrm{~kb})\end{array}$ \\
\hline DC.SOURCE & 3 & $\begin{array}{l}\text { Work from which the present resource was derived } \\
\text { DC.RIGHTS }\end{array}$ \\
\hline DC.COVERAGE & 3 & $\begin{array}{l}\text { Information about rights held over the resource for } \\
\text { reproduction or use }\end{array}$ \\
\hline
\end{tabular}


It seems that the DC.RIGHTS element in particular is less useful in a corporation than it is in a library or other public network. Materials produced within the company are inherently owned by the company and are rarely shared with the public. This assessment is based on the assumption that it is natural for corporations not to include such an element in their metadata schema. In those schemas where the RIGHTS element does appear, it is commonly used for resources not produced by the corporation or for which it does not control the copyright.

It is surprising that the Dublin Core elements DC.COVERAGE, DC.SOURCE, and DC.RELATION did not appear in more of the schemas examined. In corporations where several different versions of documents may exist, it could be useful to trace certain information back to the original resource through DC.SOURCE. Reports that exist in various formats for different purposes (e.g., formal report, slide show presentation, executive summary, etc.) could be linked through DC.RELATION.

All but one of the schemas examined in this research is from a multinational corporation with offices around the world. DC.COVERAGE is especially useful in such organizations where policies and practices may differ in each country. This element can be used to identify which country or area a particular resource pertains. It could even be used to identify a particular business unit within a company. One of the analyzed schemas used it to specify the country and office a resource pertains to when the resource is not universal to all offices. The other schema uses DC.COVERAGE as an optional element in the broader meaning of the element as defined by the Dublin Core and as described in Table 3. 
Twenty of the 40 elements in the aggregate set of distinct elements are not supported by the Dublin Core. These can be grouped into two broad categories, descriptive metadata (see table 4) and administrative metadata (see table 5). Descriptive metadata are those elements that describe the authorship, publication or subject of a resource's content. For our purposes, administrative metadata is the information that pertains to the maintenance of the resource.

One of the interesting findings in this group of descriptive metadata fields is the set of elements pertaining to PRODUCT - PRODUCT.CATEGORY, PRODUCT.FAMILY, PRODUCT.PILLAR. These elements and the CUSTOMER_SOLUTION element are all from schema \#2 (see appendix A). The fine level of detail encoded in the metadata reflects how this organization is centered on products, groups of products and the customer solutions they represent. Only one other schema examined has an element pertaining to product. 
Table 4

Non Dublin Core Descriptive Metadata

\begin{tabular}{|c|c|c|}
\hline Element & Schemas & Description \\
\hline ACCESS & 1 & $\begin{array}{l}\text { Instructions to gain access to the resource } \\
\text { contents }\end{array}$ \\
\hline AUDIENCE & 2 & $\begin{array}{l}\text { Intended users for the resource (researchers, } \\
\text { salespeople, customers, etc) }\end{array}$ \\
\hline MEDIA & 1 & $\begin{array}{l}\text { Media of the original source from which the } \\
\text { present resource was derived }\end{array}$ \\
\hline NOTES & 1 & $\begin{array}{l}\text { Additional information not covered by other } \\
\text { metadata tags }\end{array}$ \\
\hline PRODUCT & 2 & Product the resource pertains to \\
\hline PRODUCT. CATEGORY & 1 & Purpose of the product \\
\hline PRODUCT.FAMILY & 1 & Family grouping of the product \\
\hline PRODUCT.PILLAR & 1 & $\begin{array}{l}\text { One of the few main research areas in which } \\
\text { the product belongs }\end{array}$ \\
\hline CUSTOMER_SOLUTION & 1 & $\begin{array}{l}\text { Type of end user system for which the } \\
\text { product was designed }\end{array}$ \\
\hline PROJECT & 1 & Project for which this resource was produced \\
\hline RATING & 1 & $\begin{array}{l}\text { Site rating (e.g., authoritative, maintained, } \\
\text { unsupported, etc.) as determined by third } \\
\text { party }\end{array}$ \\
\hline STATUS & 3 & e.g., available, currently updated, ceased, etc. \\
\hline CONTACT.OTHER & 3 & $\begin{array}{l}\text { Additional contact person (unit manager, } \\
\text { technical support, etc.) }\end{array}$ \\
\hline CONTACT.ADDRESS & 3 & $\begin{array}{l}\text { Method for reaching the contact person } \\
\text { (phone number, email address, etc.) }\end{array}$ \\
\hline
\end{tabular}

STATUS, the most frequently occurring element in the descriptive metadata, shows the importance of insuring the currency of data. One of the goals of metadata is to 
help users find the most accurate information when they need it. This element is one that can help narrow a search to retrieve the most relevant resources. In the corporate environment, that is most likely to be current data. This need for authoritative and timely data is also reflected in the RATING element. Information professionals and other select individuals in the company are given the ability to rate the content of sites.

Given that elements relating to the company's products, trade names, and customer solutions are included in popular business databases such as the Gale Group Trade and Industry Database, ABI/INFORM, and Business and Industry, the relatively low frequency of such elements in these metadata schemas is surprising to the bibliographic description community because. One possible way to account for this is that people creating metadata records who find product, customer, etc to be important are inserting the relevant information into DC.SUBJECT.CONTROLLED or DC.SUBJECT.KEYWORDS. Further research in this field should examine the contents of tags in actual records to see if this is occurring or not.

The five elements in Table 5 are those that are not essential to resource description or discovery, but provide functions that serve administrative purposes on the intranet. The desire for metadata to help users retrieve the most accurate information possible is also reflected in these metadata elements as well. DATE.PROCESSED could alert the user to resources that may have outdated metadata, a particularly useful tag for resources that change frequently. Likewise, RETENTION_PERIOD identifies when resources are to be archived and removed from the system so as not to give inaccurate or outdated information. 
Table 5

Non-Dublin Core Administrative Metadata

\begin{tabular}{lcl}
\hline \multicolumn{1}{c}{ Element } & Schemas & $\begin{array}{l}\text { Description } \\
\text { LOCATION }\end{array}$ \\
\hline INDEXED & 2 & $\begin{array}{l}\text { Server or file system where the item is located } \\
\text { spiders }\end{array}$ \\
\hline DATE.PROCESSED & 1 & Date the metadata was created for the resource \\
\hline METADATA ID & 1 & $\begin{array}{l}\text { Unique identification number for the metadata } \\
\text { record }\end{array}$ \\
\hline RETENTION_PERIOD & 1 & $\begin{array}{l}\text { Period or date after which the resource is } \\
\text { archived }\end{array}$ \\
\hline
\end{tabular}

\section{Conclusions}

This research introduced a study of metadata for corporate intranets. It sought to uncover what elements are currently being used and to compare corporate metadata practices with the Dublin Core Element Set. Given that 13 of the 15 most commonly used elements are from the Dublin core, it supports the goals of the Dublin Core that it be a " "core' foundation of property values and types" that are meant to promote interoperability and serve as a basic schema for extension and modification by specific groups as necessary (DCMI 2000).

One of the more notable challenges in conducting this research was in finding participants. One possible reason for the low response rate is that since this is a relatively new field few companies are actually using metadata to manage their intranets. Also, three companies declined to contribute schemas because they have multiple schemas for 
different divisions within the company. The proprietary nature of these schemas was also a factor in the low turnout. Organizations put a great amount of effort into developing these schemas and are not likely to give away anything that might help a competitor. Some corporations indicated such reasons for not being able to participate in this research. Ideally, there would have been sufficient schemas to perform statistical analyses on the data that could be extrapolated to the community as a whole but that was not possible at this time.

Even though some organizations could not provide schemas for this research their feedback did reflect on the current state of metadata implementations. As mentioned above, three corporations indicated that they have multiple schemas supporting different business units while one company combined several different ones. Five others responded that their schemas are proprietary information and they cannot share but noted that they are actively developing and using metadata for resource description in their company. Six individuals, two of whom provided schemas, requested a copy of this research to help with their own schema development efforts. The other four contributors in this group do not currently have a metadata schema but they are considering it as one option for alleviating the information retrieval difficulties on their own intranets.

Four companies, two of which requested a copy of these findings, indicated that they are in the process of developing metadata schemas for their intranets so they could not provide a working schema at this time. Additionally, one information provider that develops products for intranet portals and integrated content delivery services is interested in acquiring this research to aid in their own product development efforts. 
Two of the companies that provided metadata schemas for this research request that research and reports from external consultants come with a modified metadata record. Upon receipt, these reports can be made available over the intranet quickly with little processing. As more companies begin to request that basic metadata records be supplied with information they purchase, these information providers are more likely to cooperate if the organizations they deal with use a similar schema. Such efforts could be greatly enhanced if corporations used the Dublin Core metadata elements, as defined by the DCMI, for their basic schema. Such a base schema would also facilitate the integration of information after mergers and acquisitions. Moreover, in a study of users' perceptions of information retrieval after implementing a metadata schema on the corporate intranet, one of the contributors to this research found that nearly $70 \%$ of respondents felt that their intranet searches returned more useful documents.

These anecdotes, in addition to the above research, all reflect recognition of the importance of metadata and a growing interest in metadata initiatives. Further research could be of great benefit to those undertaking metadata initiatives at their own corporations.

As more corporations realize that effective management and organization of their information assets means the effective management of the related metadata, they will need to reevaluate their resource description practices and to create policies if none exist. Also, if the Dublin Core gains wider acceptance as a basic set of metadata, it will allow a more fluid interchange of information between companies, clients and information providers. 
This research contributes to the rapidly growing body of literature on metadata. These findings will help the metadata community gain a wider appreciation for how their efforts are being realized in a variety of settings. Finally, it is hoped that this research will be of use to organizations interested in implementing metadata as it explores some possible elements and ways in which the Dublin Core can be enhanced for a local domain. 


\section{References}

Albert, J. (2000). Is knowledge management really the future for information professionals? In Knowledge management for the information professional. (pp 6376). Medford, NJ, Information Today, Inc.

Altman, R. L. (1999). Searching the IRN: Metadata at a corporate digital library. Master's Thesis. University of North Carolina at Chapel Hill.

Damsgaard, J., et. al. (forthcoming) Corporate intranet implementation : Managing emergent technologies and organizational practices. Journal of the association of information systems.

Dempsey, L. \& Heery, R. (1998, March). Metadata : A current view of practices and issues. Journal of documentation, 54 (2), 145-172.

Dublin Core Metadata Initiative. (2000). < http://purl.org/DC/index.htm> [2000, October 20]. 
Forsberg, K. \& Dannstedt, L. (2000). Extensible use of RDF in a business context. $<$ http://decweb.ethz.ch/WWW9/323/323.html> [2000, December 3].

Fortune. (2000). <http://www.fortune.com/> [2001, April 16].

Google. (2000). <http://www.google.com/> [2001, February 28].

Hahn, T. (1998, April/May). Text retrieval online: Historical perspectives on web search engines. Bulletin of the American society for information science, 24(4), 7-10.

Lagoze, C. (1996, July/August). The Warwick Framework : A container architecture for diverse sets of metadata. D-Lib Magazine [On-line serial]. $<$ http://www.dlib.org/dlib/july96/lagoze/07lagoze.html>

Lange, H. \& Winkler, J. (1997). Taming the internet : Metadata, a work in progress. In Advances in librarianship, 21 (pp 58-72). New York, Academic Press.

Library of Congress. (2000). <http://lcweb.loc.gov/marc/> [2000, November 20]

Medeiros, N. (2000). XML and the Resource Description Framework: The great web hope. Online magazine [On-line serial], 24(5).

http://www.onlineinc.com/onlinemag/OL2000/medeiros9.html 
Qin, J. \& Wesley, K. (1998). Web indexing with meta fields: A survey of web objects in polymer chemistry. Information technology and libraries, 17(3), 149-158.

Sullivan, D. (2000). Search engine watch. $<$ http://www.searchenginewatch.com> [2001, February 22]

Varon, E. (2000, August 1). The Langley Files. CIO magazine. [On-line serial]. $<$ http://www.cio.com/archive/080100_langley.html > [2001, March 6].

Weibel, S., Godby, J., \& Miller, E. (1995). OCLC/NCSA metadata workshop report. <http://www.oclc.org:5046/conferences/metadata/dublin_core_report.html $>$ [2000, October 1].

Younger, Jennifer A. (1997). Resources description in the digital age. Library trends, $45(3), 462-488$. 


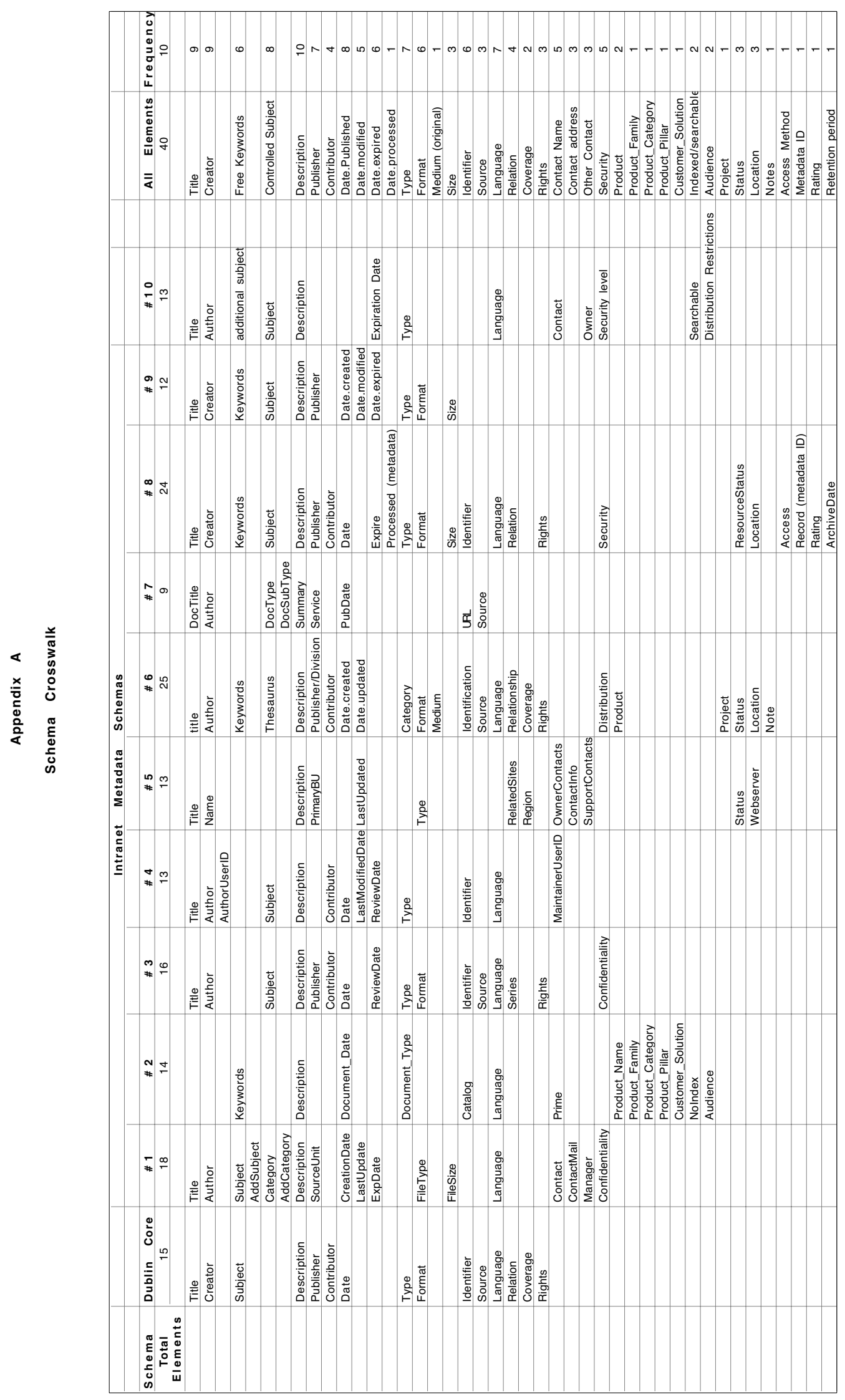

